\title{
Reflectivity and spectral attribute-based reservoir characterization: a case study from "MUN" onshore Niger delta field, Nigeria
}

\author{
J. M. Munyithya ${ }^{1,2}$ (D) C. N. Ehirim ${ }^{3} \cdot$ T. Dagogo ${ }^{3}$
}

Received: 23 October 2019 / Accepted: 3 June 2020 / Published online: 12 June 2020

(c) The Author(s) 2020

\begin{abstract}
Reservoir characterization plays a significant role in the exploration, development, and production of hydrocarbon reservoirs. The use of integrated approach in characterization improves on the accuracy, certainty, and robust interpretation of reflectivity data. The study aimed to integrate reflectivity and spectral attributes to adequately characterize hydrocarbon reservoirs in MUN onshore Niger delta field. Well log and rock physics analyses identified and delineated reservoirs, discriminated lithology, characterized fluid, and established relations between elastic and reservoir properties for field-wide interpretation of the reflectivity data. The wells were tied to the reflectivity data, and H4 seismic horizon was mapped. Subsequently, sweetness, reflectivity and spectral attributes were extracted along $\mathrm{H} 4$ horizon after inversion and spectral decomposition of the reflectivity data and independently interpreted. Channel-like structure with high-amplitudes, low-to-moderate acoustic impedance $\left(I_{\mathrm{p}}\right)$, lambda-rho $(\lambda \rho)$ and mu-rho $(\mu \rho)$ attribute values, and high-amplitude low-frequency spectral attributes (15-35 Hz), respectively, characteristics of hydrocarbon saturated channel sands were delineated. The channel reservoir sand is thick, porous with low volume of shale and low to moderate water saturation. Analysis of data further shows that reflectivity attributes provided a better description of fluid characteristics than the sweetness and spectral attributes, but are less sensitive to structure and exaggerated the shape and limits of the channel sands. However, the spectral attributes seem to be more robust than the reflectivity attributes in providing subtle structural and stratigraphic details of the reservoir as well as delineating by-passed hydrocarbons in the field.
\end{abstract}

Keywords Spectral attributes $\cdot$ Reflectivity attributes $\cdot$ Reservoir characterization $\cdot$ Cross-plots

\section{Introduction}

Reflectivity and spectral attributes derived from well and seismic dataset have become potent and robust tools in reservoir characterization, relating seismic responses to reservoir properties. Predrill reservoir characterization is key

J. M. Munyithya

jmmunyithya@jkuat.ac.ke

C. N. Ehirim

ehirimcn@yahoo.com

T. Dagogo

nengi.dagogo@uniport.edu.ng

1 World Bank, ACE-CEFOR, UNIPORT, East West Rd, Choba, P.M.B 5323, Port Harcourt, Rivers State, Nigeria

2 Physics Department, JKUAT, Box 62000 00200, Nairobi, Kenya

3 Physics Department, UNIPORT, Box 122, Choba, Port Harcourt, Nigeria in estimating the potential for hydrocarbon accumulation and production (Mohamed et al. 2016; Ehirim and Akpan 2017). Characterization entails adequate description of the reservoir properties and structure for improved exploitation and production of hydrocarbons.

Reservoirs are characterized by their properties such as fluid types, water saturation, volume of shale, porosity, permeability, pressure, temperature, thickness, and depth. Therefore, hydrocarbon reservoir characterization is the mapping of geometry, structure/stratigraphy and estimation of relevant properties of the potential reservoir (Eshimokhai and Akhirevbulu 2012; Ajisafe and Ako 2013; Edigbue et al. 2014; Mahmoud et al. 2016; Sanuade et al. 2017).

Seismic reflectivity is an interface related property of the seismic signal, which occurs due to the contrast in elastic properties across a geologic interface. The nature of the interface, source wavelet, and the contrasting properties of the geologic layers determine the magnitude, phase and polarity of the reflectivity signal. This signal carries 
information about the lithology, pore fluids, structure/stratigraphy and geometry of the reservoir (Hilterman 2001).

Through acoustic impedance inversion, these reservoir properties can be estimated from reflectivity attributes extracted from the resulting acoustic impedance data. Reflectivity attributes such as acoustic impedance, Poisson impedance, $\mathrm{VpVs}$ ratio, Lambda rho, and Mu rho have been employed routinely to distinguish lithology and characterize pore fluids (Hamada 2004; Ekwe et al. 2012; Bello et al. 2015).

Spectral attributes derived from decomposition of seismic reflectivity data in time to their component frequency bands is effective for qualitative and quantitative interpretation of bed thickness, lithology, discontinuities, channels, pore fill and structure (Marfurt and Kirlin 2001; Ahmad and Rowell 2012; Wei et al. 2019), as well as for direct hydrocarbon indicator for gas charged reservoirs (Sinha et al. 2005). Amplitude-frequency anomalies have always been interpreted as hydrocarbon saturated porous thin/thick reservoir beds (Ahmad and Rowell 2012; Ehirim and Akpan 2017).

Integrating reflectivity and spectral attributes in reservoir studies enhances hydrocarbon detection, delineation, and reservoir characterization (Tian et al. 2010). These therefore ensures that fails hydrocarbon shows and drilling of dry holes are avoided and consequently, informed decisions regarding hydrocarbon prospectivity, producibility and drilling locations for wells could be made.

The present study is aimed at integrating reflectivity and spectral attributes derived from well and 3D Post-Stack time migrated (PSTM) reflectivity data to improve reservoir detection, delineation and characterization in MUN Niger Delta Onshore field. This study was carried out in the coastal swamp depobelt of the Niger Delta (Fig. 1). The Niger Delta Basin, situated at the apex of the Gulf of Guinea on the West Coast of Africa, is one of the most prolific deltaic hydrocarbon provinces in the World (Ajisafe and Ako 2013). It covers an area within longitude $4^{\circ} \mathrm{E}-9^{\circ} \mathrm{E}$ and latitudes $4^{\circ} \mathrm{N}-9^{\circ} \mathrm{N}$. The swamp depobelt is characterized by rain forest and mangrove vegetations, with landscape incised by numerous brackish rivulets and creeks, high precipitation and relative humidity.

\section{Geology of the study area}

The Niger Delta is composed of an overall regressive clastic sequence of Tertiary age (Evamy et al. 1978). The Delta has prograded southwards overtime forming depobelts, namely Northern, Ughelli, Central swamp, Coastal swamp

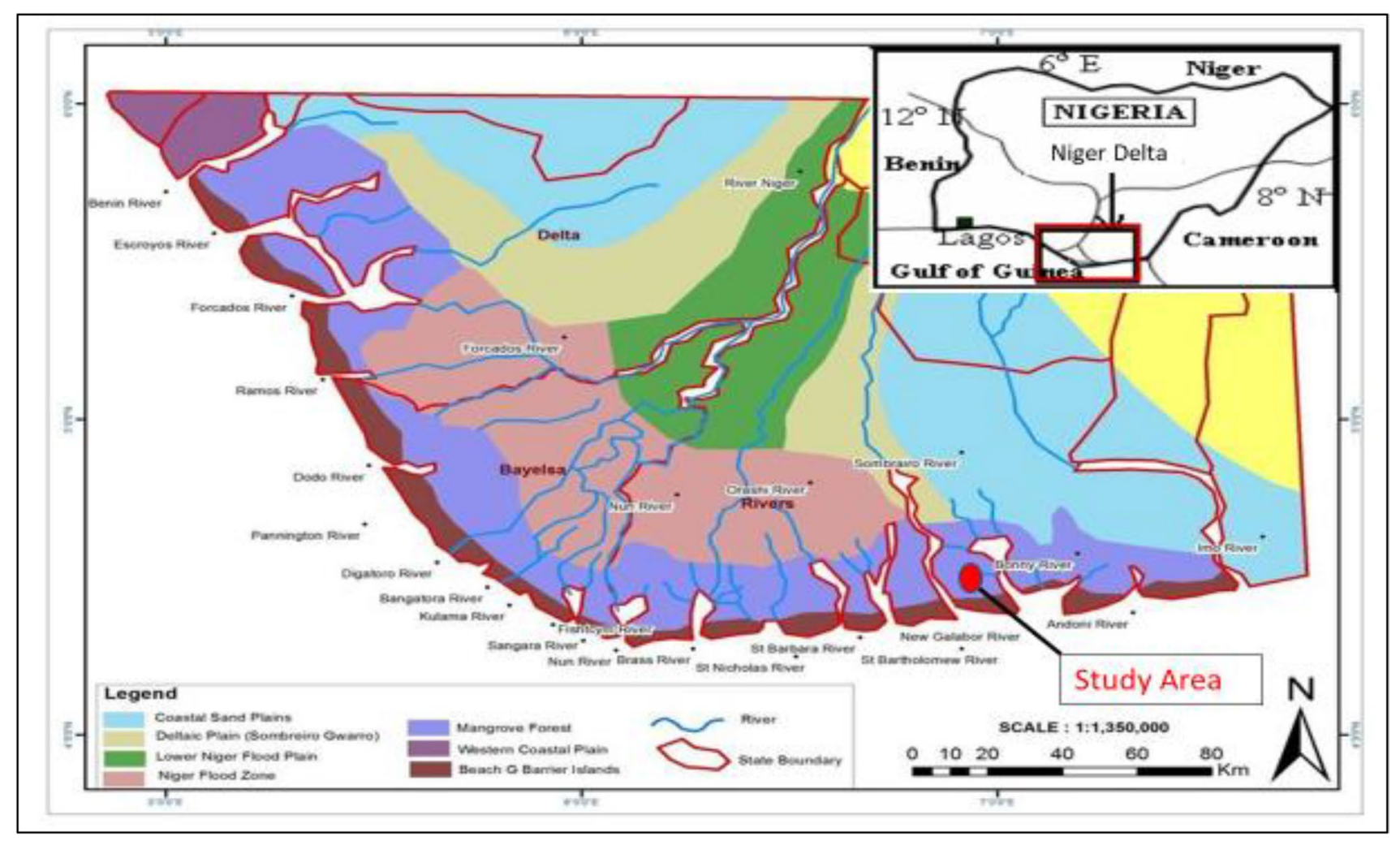

Fig. 1 Location map of the study area (Reijers 2011) 


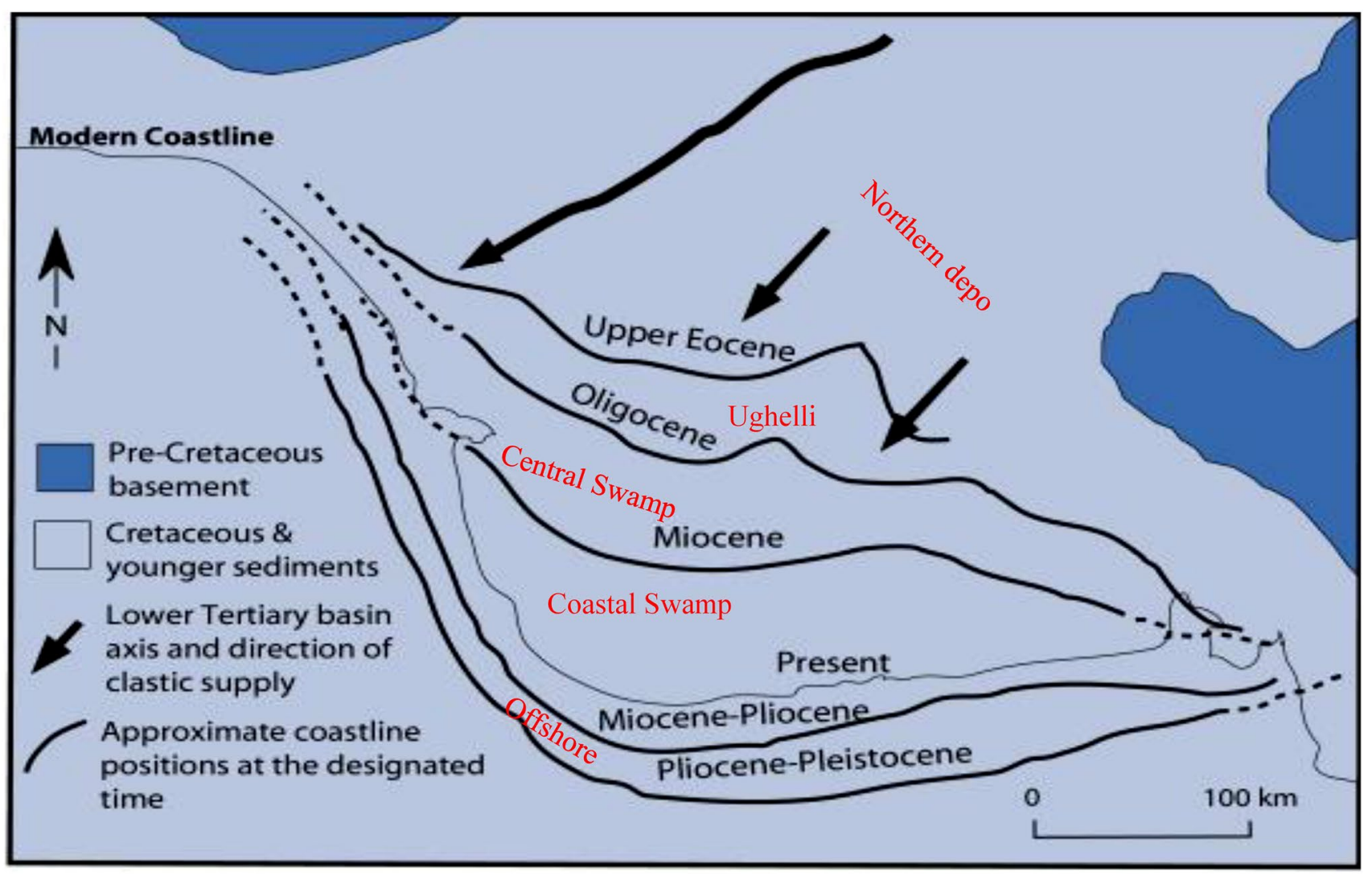

Fig. 2 Depobelts and direction of sediment deposition in Niger delta (Tuttle et al. 1999)

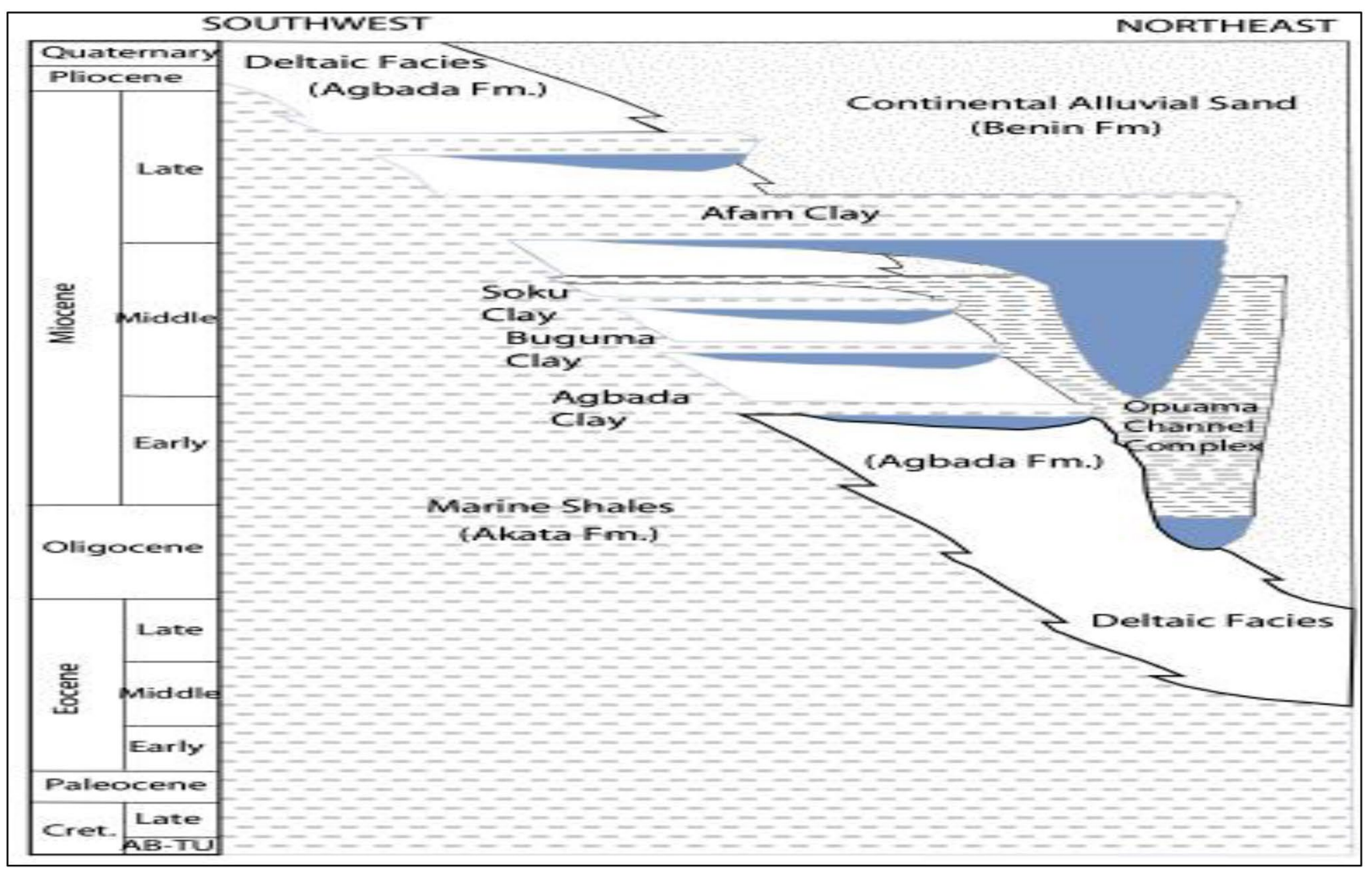

Fig. 3 Geologic map of Niger delta (Tuttle et al. 1999) 
and Offshore depobelts, each with its own sedimentation, deformation and petroleum history (Fig. 2), that represents the most active portion of the delta at each stage of its development. These depobelts coalesced in time to form one of the largest and massive regressive deltas in the world (Doust and Omatsola 1990).

The Tertiary section of the Niger Delta is divided into three formations: Benin, Agbada (the reservoir rock) and Akata (the source rock and reservoir in deep offshore) Formations (Fig. 3). The Niger delta province has been identified to have only one petroleum system referred to as the Akata-Agbada Tertiary Niger Delta petroleum system (Tuttle et al. 1999). Early global plate tectonic movements and local gravity tectonics caused deformation of the Agbada Formation, resulting into anticlinal and growth fault structures in the formation. These structures controlled the subsequent sedimentation, migration and accumulation hydrocarbons in the Agbada Formation.

\section{Methodology}

Data used in this study are well logs with corresponding check shot information from wells 14, 15 and 16 and 3D post-stack time migrated (PSTM) reflectivity volume of
"MUN" onshore Niger delta field. These datasets were loaded into the software (Petrel and HR) and quality checked for spurious and missing data points. Well log analysis, petrophysical modelling, reflectivity inversion and spectral decomposition are the methods adopted to achieve the aim of this study (Fig. 4).

The well logs: density (RHOB), Gamma ray (GR), resistivity (RT) and sonic (Vp), were used to discriminate lithologies into sand and shale formations and characterize pore fluids at the wellbore (Fig. 5).

Pseudo-logs of well-based seismic elastic properties were generated, cross-plotted and color coded with reservoir properties in 3-D cross-plot space with the aim of discriminating lithology, characterize pore fluids and establish relations between seismic elastic properties and reservoir properties. Well correlation, time-depth conversions and seismic to well tie were done to facilitate horizon mapping on the seismic data. Subsequently, three horizons were mapped, namely $\mathrm{HA}, \mathrm{H} 4$ and $\mathrm{H} 7$, guided by respective reservoir sand markers in the wells (A, 4 and 7). For the purpose of this study, sand 4 and $\mathrm{H} 4$ seismic horizon were used for analysis.

Amplitude-related attribute (sweetness) was extracted along $\mathrm{H} 4$ horizon to identify and delineate hydrocarbon zones. Subsequently, the reflectivity data was inverted into

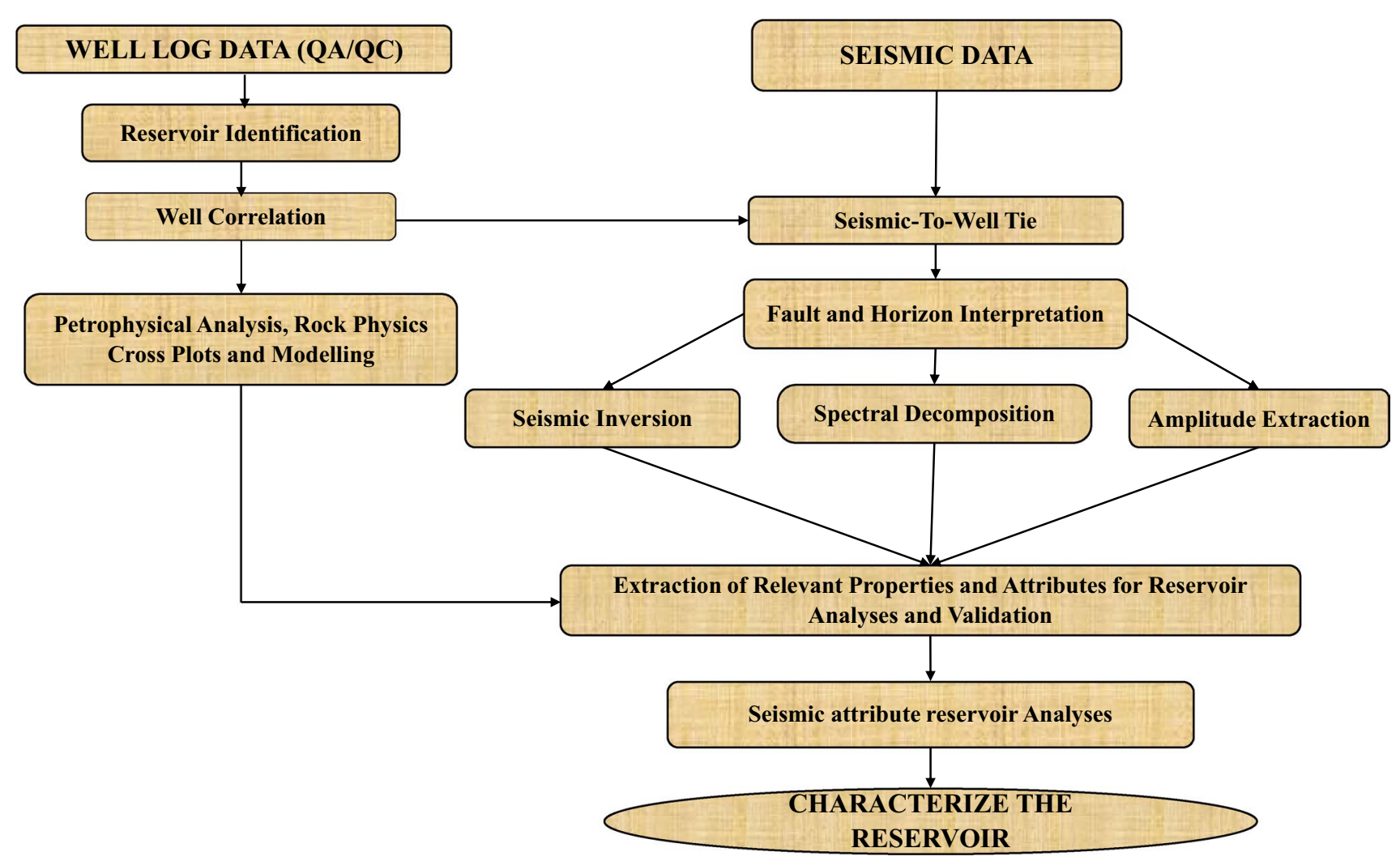

Fig. 4 Schematic workflow of the study 


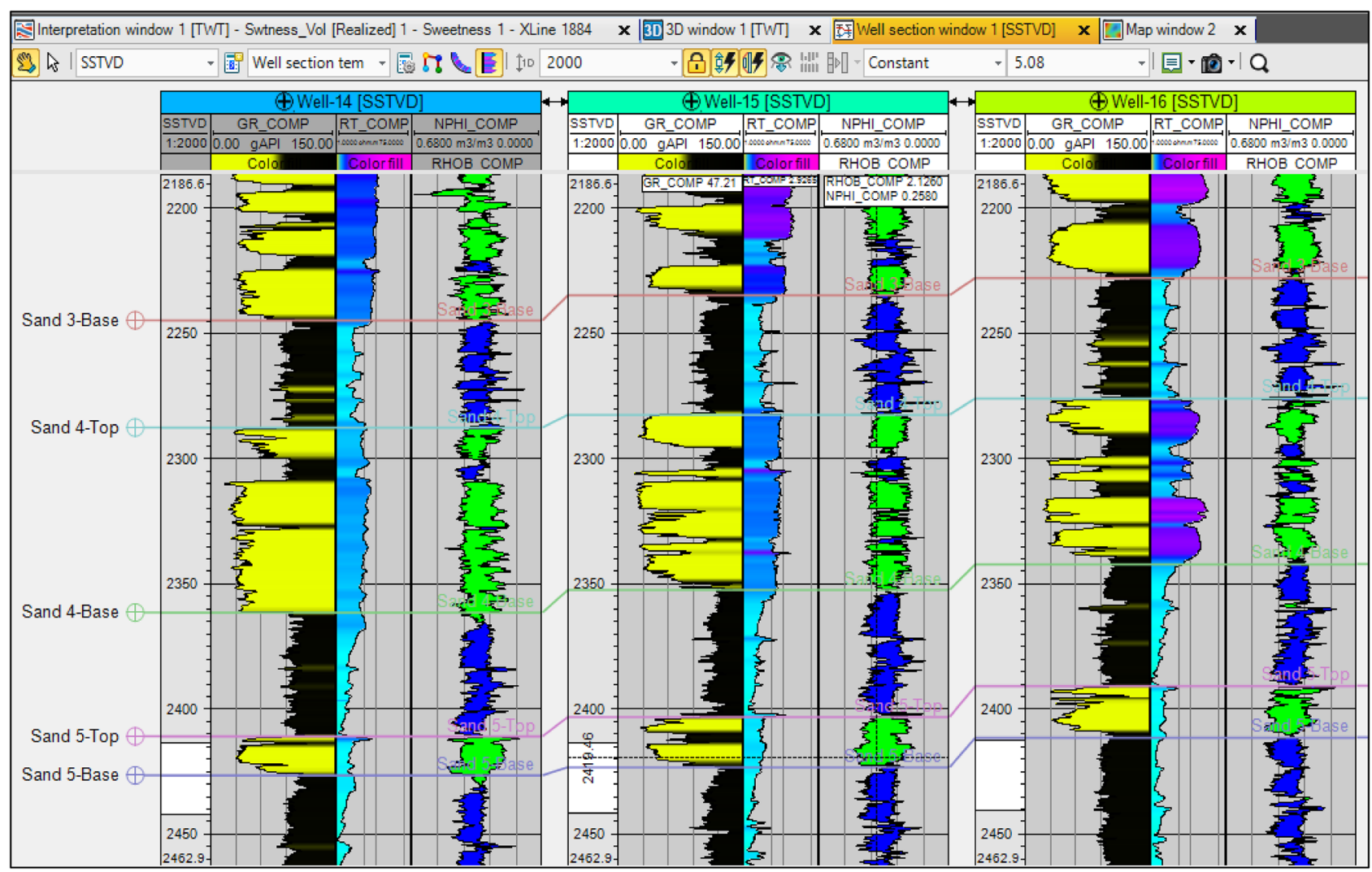

Fig. 5 Well logs, mapped reservoirs and correlation across the wells

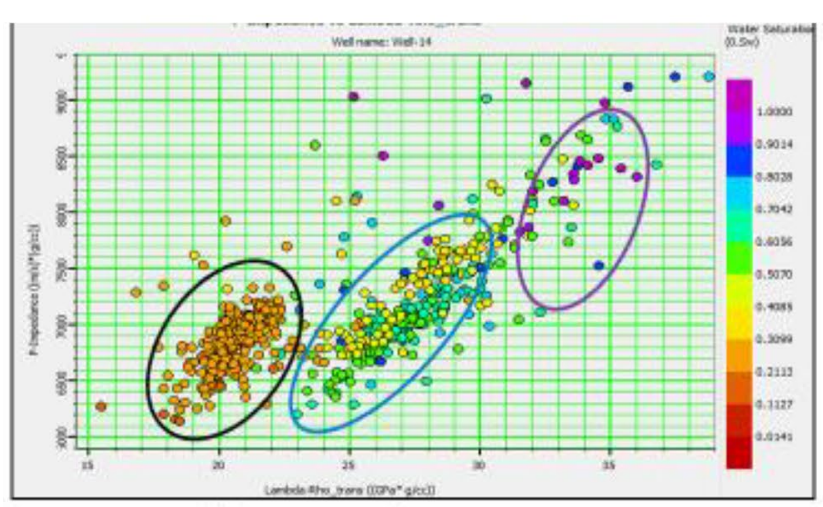

(a) Water saturation

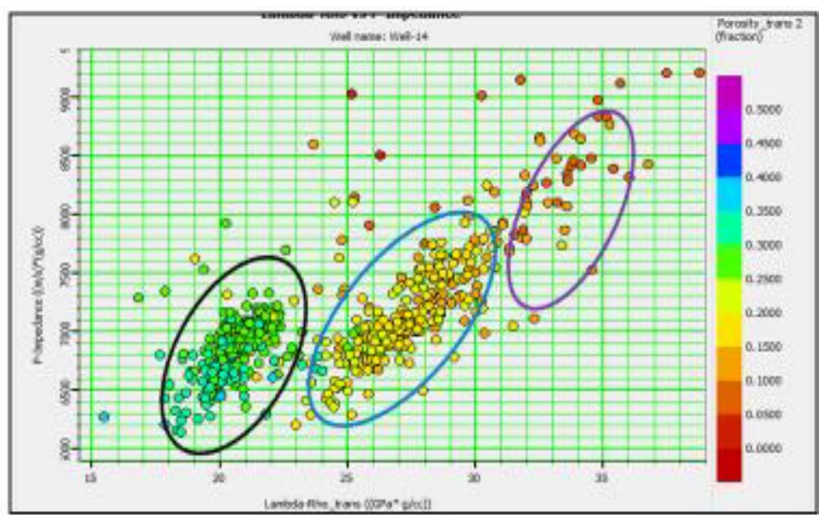

(b) Porosity

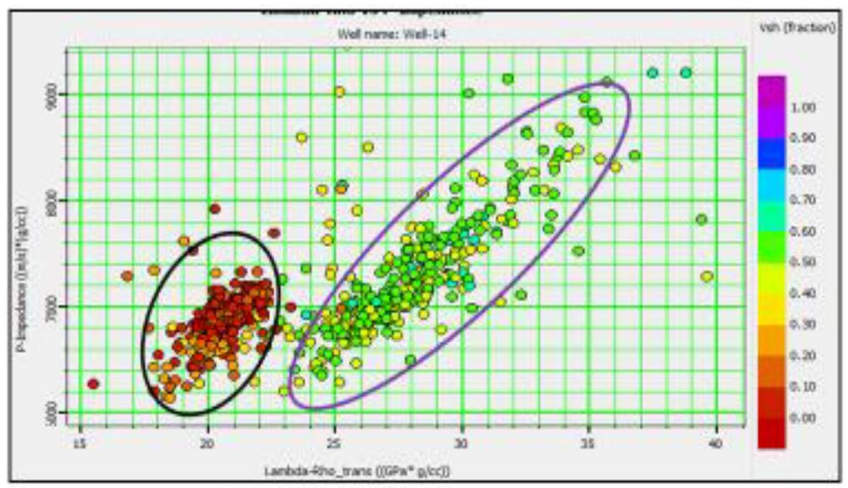

(c) Shale volume

Fig. 6 Cross-plots of acoustic impedance $\left(I_{\mathrm{p}}\right)$ versus lambda-rho $(\lambda \rho)$, color coded with a water saturation, b porosity and $\mathbf{c}$ shale volume for SAND 4 


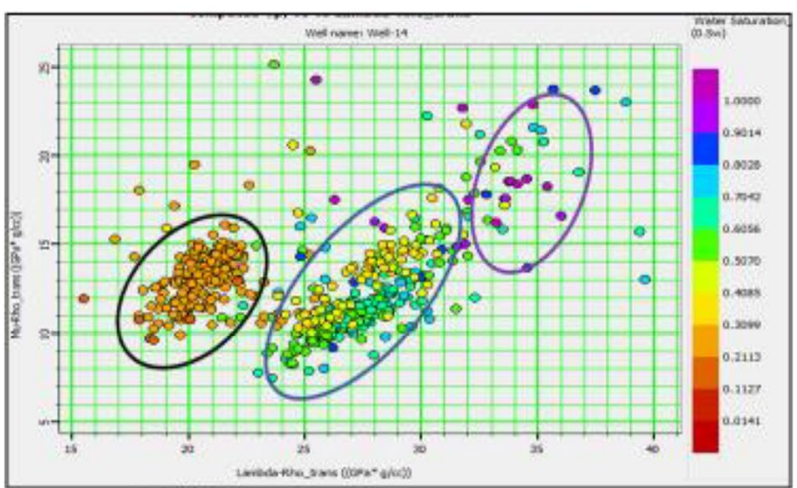

(a) Water saturation

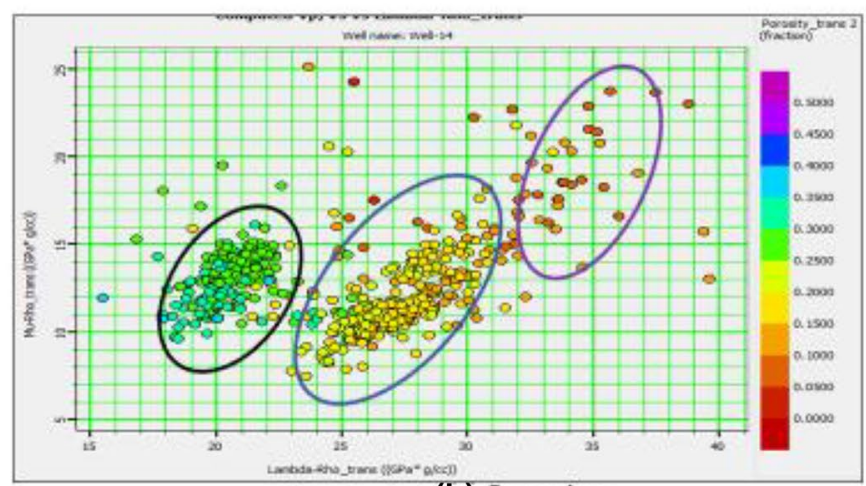

(b) Porosity

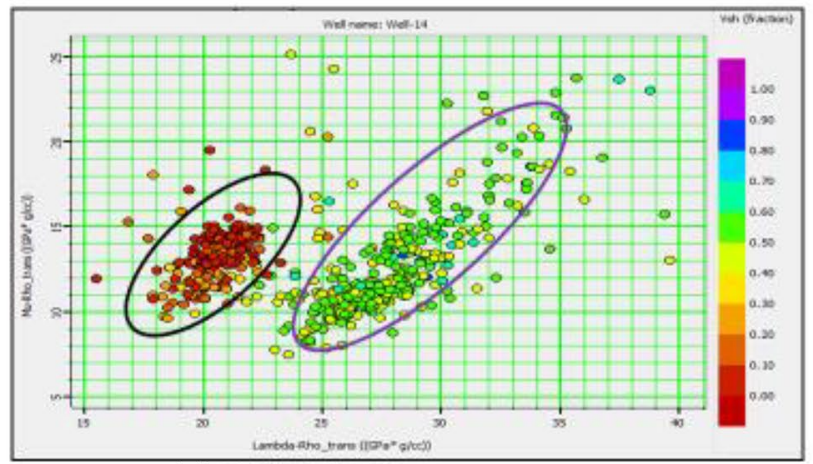

(c) Shale volume

Fig. 7 Cross-plots of mu-rho $(\mu \rho)$ versus lambda-rho $(\lambda \rho)$, color coded with a water saturation, b porosity and $\mathbf{c}$ shale volume for SAND 4

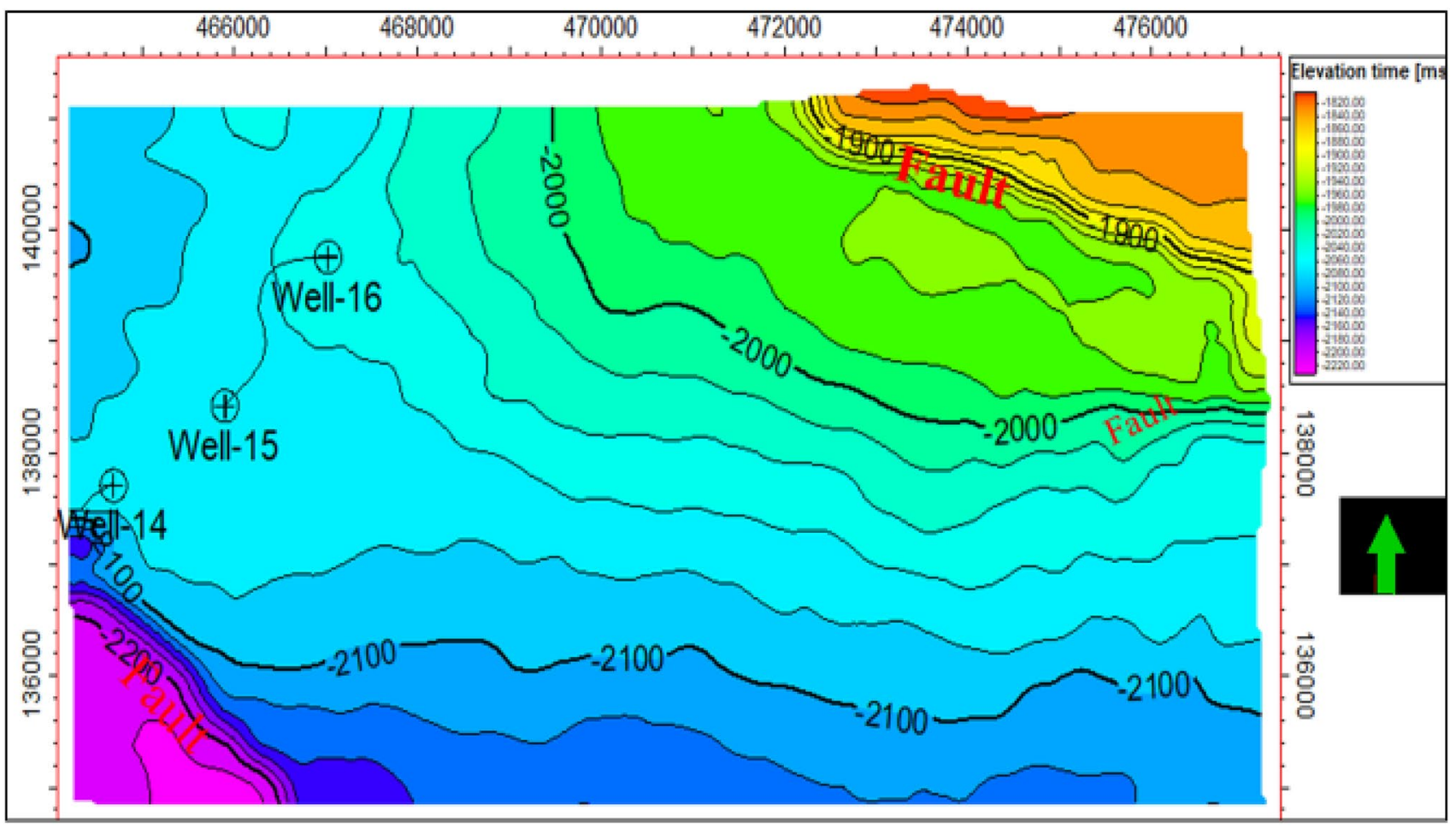

Fig. 8 Time structure map along H4 horizon 


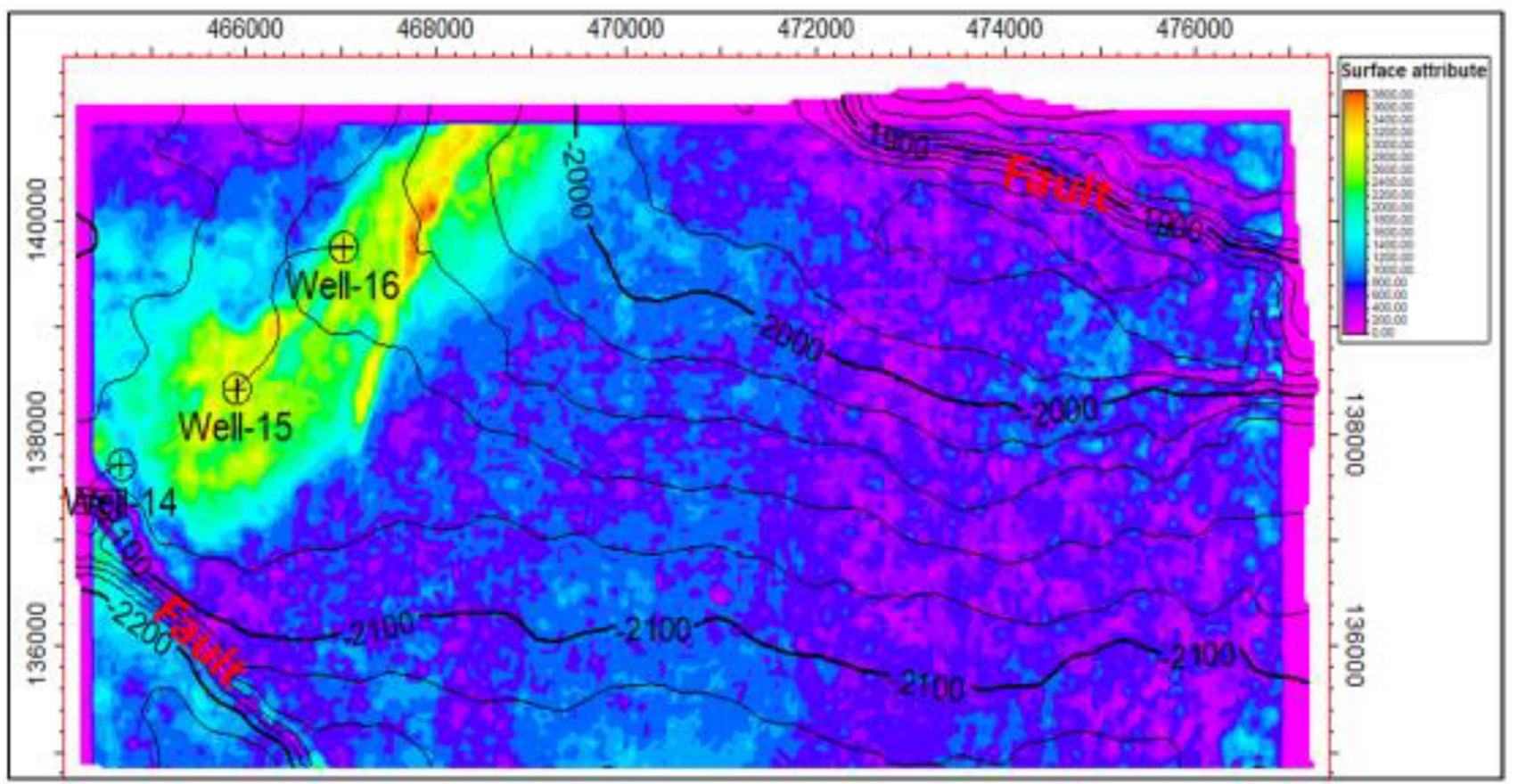

Fig. 9 Extracted sweetness attribute map along H4 horizon

acoustic impedance volume using model-based inversion scheme which involves generating low-frequency model, guided by well-logs and interpreted horizons. The acoustic impedance attribute was extracted along $\mathrm{H} 4$ horizon from the impedance volume. Other attributes such as lambda-rho and mu-rho were generated to fieldwide characterize the reservoir.

Furthermore, spectral frequency volume was generated using a continuous wavelet transform (CWT) decomposition method. The method convolves the time-dependent reflectivity data with a suitable mother wavelet to produce a frequency volume. Spectral attribute slices were then extracted from the volume along $\mathrm{H} 4$ seismic horizon but within the seismic band width of the seismic data and analyzed to delineate possible structures, evaluate indication of hydrocarbons and determine hydrocarbon presence and distribution in the field.

\section{Presentation of results}

The results of well log evaluation, petrophysical modelling (cross-plots), reflectivity inversion and spectral decomposition are presented and analyzed. Three reservoirs were delineated by low gamma ray ( $<75$ API) and high resistivity $(>500 \Omega \mathrm{m}$ ) values with average thickness of $67 \mathrm{~m}$ (Dagogo et al. 2016).

Well-based seismic elastic properties were cross-plotted and color coded with reservoir properties in 3D cross-plot domain. Results show that $I_{\mathrm{p}}$ versus $\lambda \rho$ and $\mu \rho$ versus $\lambda \rho$ property pairs were more robust in lithology identification and fluid prediction than other cross-plotted property pairs. Analysis of the results show that hydrocarbon saturated sands (black oval) depict low $\lambda \rho$ and low to moderate $I_{\mathrm{p}}$ and $\mu \rho$ values corresponding to low $S_{\mathrm{w}}$ and $V_{\mathrm{sh}}$ and high $\phi$ (Figs. 6, 7). Brine sands (blue oval) and shale (purple oval) have high $I_{\mathrm{p}}, \lambda \rho$ and $\mu \rho$ corresponding to high $S_{\mathrm{w}}$ and $V_{\mathrm{sh}}$, and low $\phi$ values (Ehirim and Dagogo 2016).

Time structure map extracted along H4 seismic horizon show gradual topographical gradient NE to SW (Fig. 8). The wells are in moderate topography between low time (SW) and high time (NE), bounded by two major NW-SE growth faults in the NE and SW of the map, respectively.

Sweetness attribute analysis along $\mathrm{H} 4$ seismic horizon show elongated high-amplitude anomalous zone (sweet zone) especially around the well locations bounded by growth faults to the NE and SW (Fig. 9), interpreted as a channel sand. Sweet zone is a direct indicator of thick and porous hydrocarbon saturated sand (Hart 2008). Amplitude brightening to the NE of the existing wells in the channel could be indications of by-passed hydrocarbons. The reduction in amplitude to NW and SE of the channel sand shows the limit of hydrocarbon saturated channel sands in the field.

The reflectivity attributes [acoustic impedance $\left(I_{\mathrm{p}}\right)$, lambda-rho $(\lambda \rho)$ and mu-rho $(\mu \rho)]$ extracted along $\mathrm{H} 4$ seismic horizon are characterized by elongated structures of low attribute values interpreted as channel sands with probable hydrocarbon saturation (Fig. 10a-c). 
Fig. 10 Rock attributes horizon maps showing a acoustic impedance, $\mathbf{b}$ lambda-rho and $\mathbf{c}$ mu-rho along $\mathrm{H} 4$ horizon (a) Acoustic Impedance

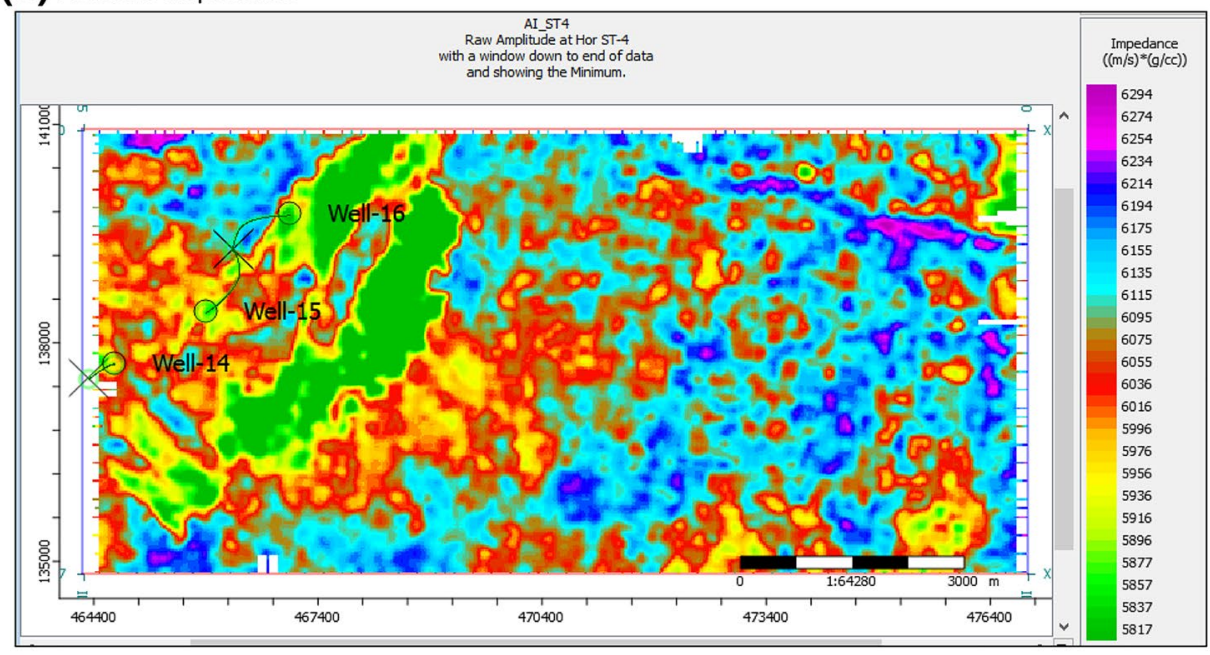

(b) Lambda-rho

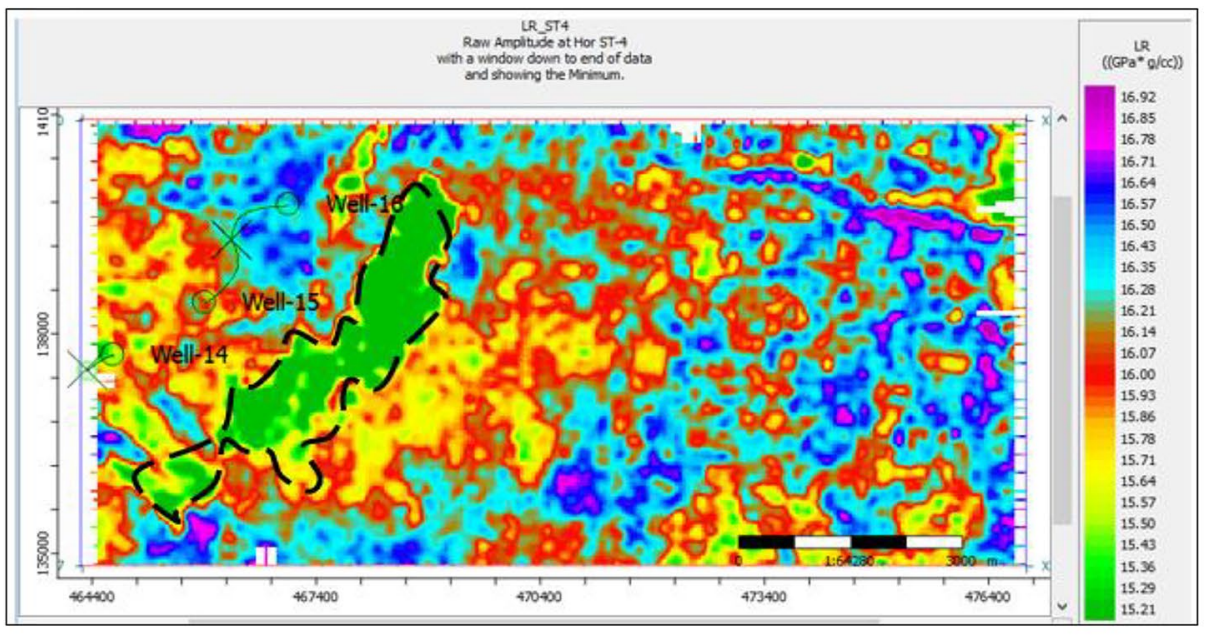

(c) Mu-rho

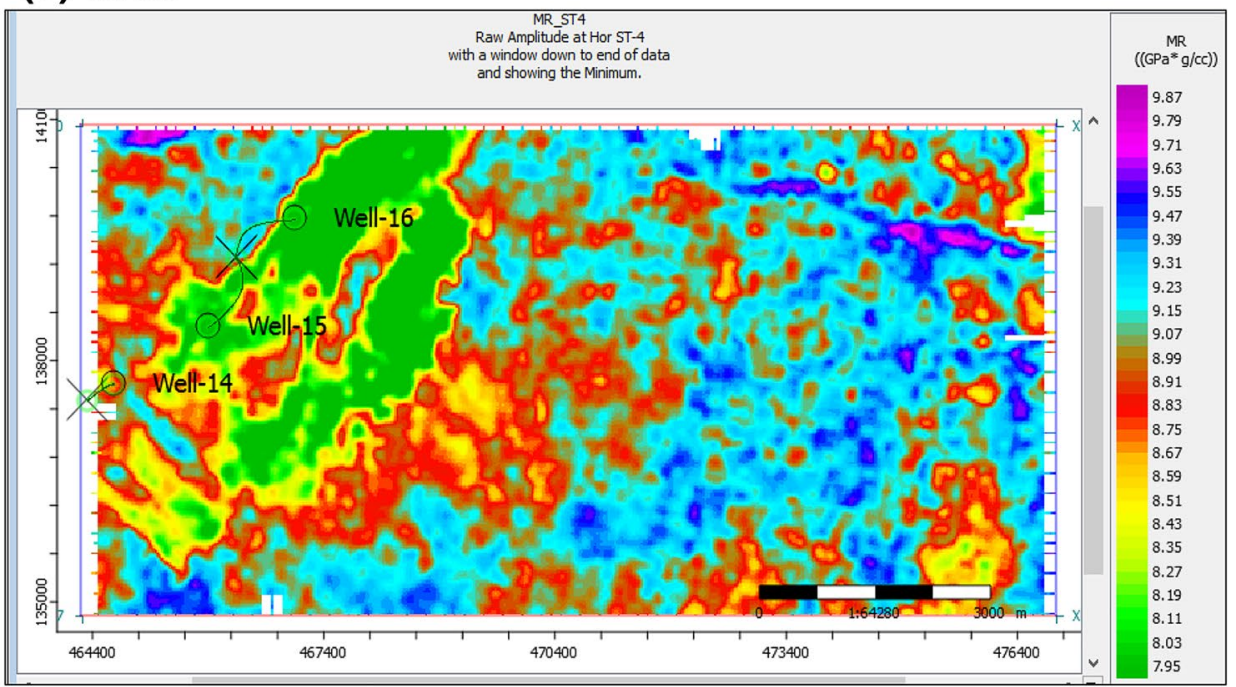




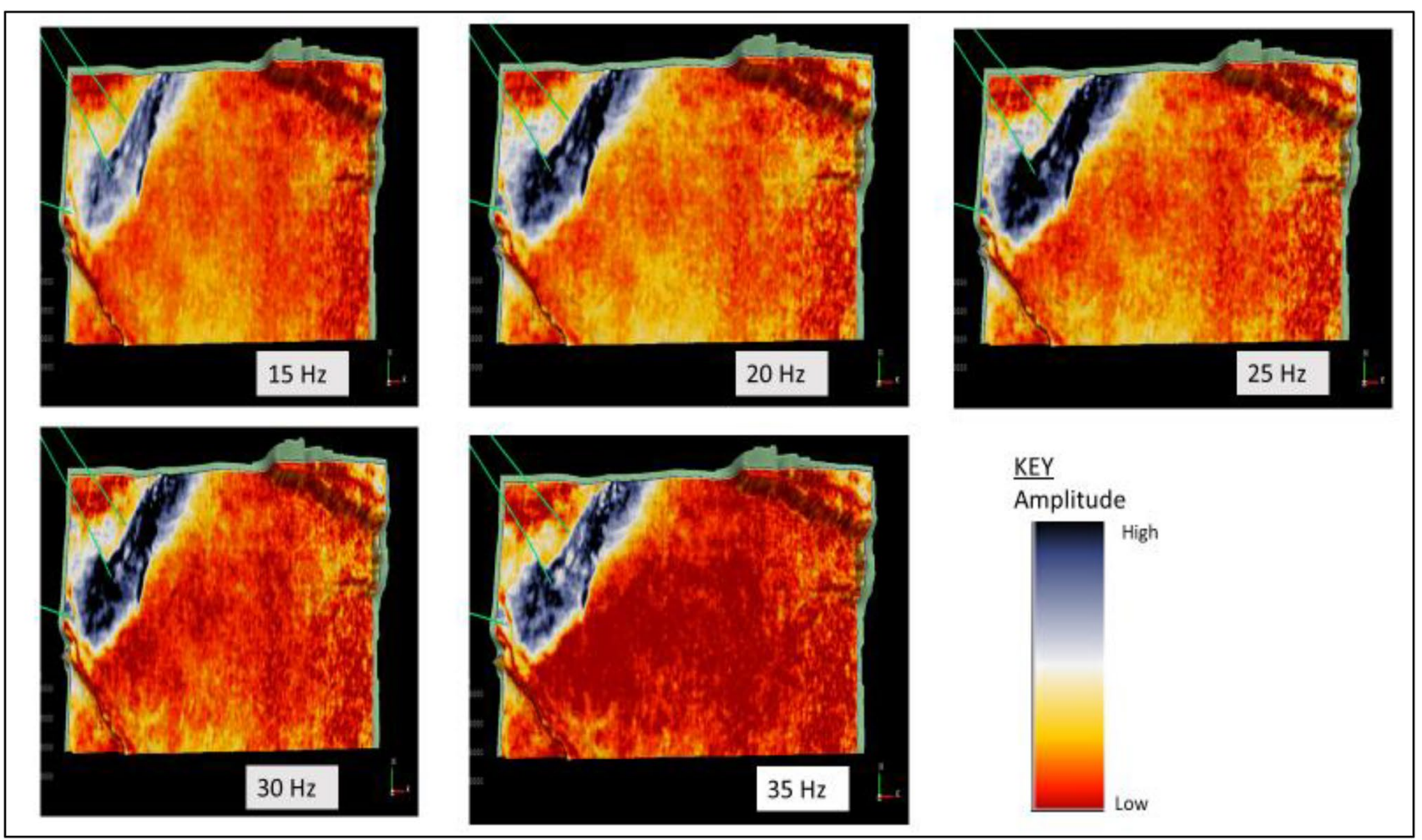

Fig. 11 Spectral frequency attribute slices, 15-35 Hz along H4 horizon

The $I_{\mathrm{p}}$ and $\mu \rho$ sections exhibit similar amplitude patterns. They delineated two parallel NE-SW channel structures and with the wells lying on low attribute values. These structures are elongated and well resolved in the $\mu \rho$ than $I_{\mathrm{p}}$ section. However, the $\lambda \rho$ section show complete disappearance of the NW channel sand structure while the SE channel structure was well imaged. Wells 14 and 15 lies on low $\lambda \rho$ values while well 16 lie on high $\lambda \rho$ in contrast to the $I_{\mathrm{p}}$ and $\mu \rho$ sections.

$I_{\mathrm{p}}$ is sensitive to rock matrix and fluid in the rock formation and thus its low value is a reflection of both sand formation and hydrocarbon fluid constituent. On the other hand, low $\lambda \rho$ and $\mu \rho$ distinctly reflect hydrocarbon charged sands and rock matrix, respectively. Therefore, low to moderate $I_{\mathrm{p}}, \lambda \rho$ and $\mu \rho$ attribute values suggest porous hydrocarbon saturated reservoir channel sands. However, the $\lambda \rho$ section show that well16 and the surrounding vicinity lie on high $\lambda \rho$ value indicating that this well and their surroundings have watered out, while wells 14 and 15 lie on low and moderate $\lambda \rho$ values, respectively, indicating hydrocarbon saturation. Moderate to high values of $I_{\mathrm{p}}, \lambda \rho$ and $\mu \rho$ are associated with brine saturated sands or shale (Goodway et al. 1997; Ehirim and Dagogo 2016; Dagogo et al. 2016).
The channel sand structure SE of the existing wells exhibit low attribute values of $I_{\mathrm{p}}, \lambda \rho$ and $\mu \rho$ and is interpreted as a by-passed play. The NW-SE growth faults bounding the channels as seen in the structural and sweetness maps were poorly imaged in the $I_{\mathrm{p}}, \lambda \rho$ and $\mu \rho$ sections. This suggests that these attributes are fairly sensitive to structure and could hardly be used for structural analysis.

Spectral attribute slices of $15-35 \mathrm{~Hz}$ frequency band extracted along $\mathrm{H} 4$ seismic horizon delineated a high-amplitude low-frequency anomalous channel structure trending NE-SW and bounded by growth faults to the NE and SW, respectively, indicating porous and thick hydrocarbon reservoir saturated sands (Fig. 11). The most resolute spectral attribute is the $25 \mathrm{~Hz}$ attribute, which coincidentally is the dominant frequency of the seismic data. Wells 14 and 15 lies on this high-amplitude low-frequency anomaly while well 16 lie on low-amplitude low-frequency zone characteristic of hydrocarbon depleted zone (Othman et al. 2016; Ehirim and Akpan 2017). East of the producing wells on the channel structure is characterized by low-frequency high-amplitude anomalies, which could likely be by-passed hydrocarbon charged sands. 


\section{Discussion of results}

Reflectivity and spectral attributes analyses was carried out in MUN onshore Niger delta field using well and 3D (PSTM) reflectivity data sets to identify hydrocarbon charged reservoir channel sands, characterize the reservoir channel sand and delineate by-passed hydrocarbons. Three reservoirs (SAND A, 4 and 7) were delineated by low GR and high resistivity log values across the three wells with an average thickness of $67 \mathrm{~m}$. SAND 4 reservoir was used for the present analyses because of its excellent reservoir properties. Petrophysical analyses reveal that SAND 4 reservoir is dominantly sandy with low volume of shale and high porosity, characteristic of the Agbada Formation.

Seismic elastic properties were cross-plotted at SAND 4 reservoir interval ( $I_{\mathrm{p}}$ vs $\lambda \rho$ and $\mu \rho$ vs $\lambda \rho$ ), color coded with the reservoir properties $\left(\phi, S_{\mathrm{w}}\right.$ and $\left.V_{\mathrm{sh}}\right)$ in 3D cross-plot domain. The crossplots delineated lithologies, characterize pore fill and established relations between seismic elastic properties and reservoir properties at the well scale. The cross-plot of $I_{\mathrm{p}}$ versus $\lambda \rho$ delineated hydrocarbon charged sands with low $\lambda \rho$ and low to moderate $I_{\mathrm{p}}$ property values, while $\mu \rho$ versus $\lambda \rho$ cross-plot delineated the reservoirs' sand matrix by low $\mu \rho$ and low $\lambda \rho$ for hydrocarbon charged sands (Goodway et al. 1997; Ehirim and Dagogo 2016).

Sand matrix is usually rigid and exhibit high $\mu \rho$ values (Chopra and Marfurt 2007). However, the low $\mu \rho$ sands delineated in this study could be attributed to the reservoir sands being unconsolidated (Goodway et al. 1997; Dagogo et al. 2016). The low $\lambda \rho$ and low to moderate $I_{\mathrm{p}}$ associated with hydrocarbon saturated sands, corresponds to low water saturation $\left(S_{\mathrm{w}}\right)$ and volume of shale $\left(V_{\mathrm{sh}}\right)$ and high reservoir porosity $(\phi)$. These well-based established relations between the seismic elastic and reservoir properties were then used to constrain the interpretation of reflectivity attributes in order to characterize the reservoir field wide and delineate by-pass hydrocarbons.

Sweetness reflectivity attribute extracted along $\mathrm{H} 4$ horizon delineated channel-like structure of hydrocarbon saturated sands as high-amplitude zones (sweet spots). The high-amplitude anomalous zones show non-uniformity in amplitude intensity distribution, suggesting probable pore fill changes, especially around the producing wells (Hart 2008; Ahmad and Rowell 2012).

Inversion of reflectivity data and extraction of $I_{\mathrm{p}}, \lambda \rho$ and $\mu \rho$ reflectivity attributes along $\mathrm{H} 4$ seismic horizon delineated channels-like structures of probable hydrocarbon saturation. These structures are elongated and more resolved in the $\mu \rho$ than $I_{\mathrm{p}}$ section. This could be explained by the heightened sensitivity of $\mu \rho$ to lithology than $I_{\mathrm{p}}$. Wells 14,15 and 16 lies on low $I_{\mathrm{p}}$ and $\mu \rho$ attribute values. However, the $\lambda \rho$ section show complete disappearance of the NW channel sand structure because of hydrocarbon depletion, while the SE channel structure saturated with hydrocarbons was well imaged. Wells 14 and 15 lies on low $\lambda \rho$ values while well 16 lie on high $\lambda \rho$.

Low to moderate $I_{\mathrm{p}}, \lambda \rho$ and $\mu \rho$ attribute values suggests porous hydrocarbon saturated reservoir channel sands with low $S_{\mathrm{w}}$ and $V_{\mathrm{sh}}$ and high $\phi$, in line with the results of the well-based cross plot analyses (Goodway et al. 1997; Ekwe et al. 2012; Dagogo et al. 2016). However, the $\lambda \rho$ section show that well 16 and the surrounding vicinity lie on high $\lambda \rho$ value indicating that this well and their surroundings have watered out, while wells 14 and 15 lie on low and moderate $\lambda \rho$ values, respectively, suggesting hydrocarbon saturation. This explains the disappearance of the NW channel sand structure on the $\lambda \rho$ section as was initially observed on the $I_{\mathrm{p}}$ and $\mu \rho$ sections. The channel sand structure SE of the existing wells exhibit low attribute values of $I_{\mathrm{p}}, \lambda \rho$ and $\mu \rho$ and is therefore, interpreted as a by-passed play. The NW-SE growth faults bounding the channels as seen in the structural and sweetness maps were poorly imaged in the $I_{\mathrm{p}}, \lambda \rho$ and $\mu \rho$ sections. This suggests that these attributes are fairly sensitive to structure and could hardly be used for structural analysis.

The spectral attribute slices $(15-35 \mathrm{~Hz})$ extracted along $\mathrm{H} 4$ horizon via spectral decomposition of the reflectivity data, delineated thick and porous channel-like structure of hydrocarbon saturated sands as high-amplitude low-frequency anomalies (Partyka et al. 1999; Marfurt and Kirlin 2001; Ehirim and Akpan 2017). The most resolute and robust spectral attribute is the $25 \mathrm{~Hz}$ attribute which coincidentally is the dominant frequency of the seismic data. Wells 14 and 15 lies on this high-amplitude low-frequency anomaly while well 16 lie on low-amplitude low-frequency zone characteristic of hydrocarbon depleted zone in line with the result of the $\lambda \rho$ attribute.

However, the non-uniformity in the intensity of the spectral anomalies suggests thickness and pore fill variations along the channel structure in the field (Partyka et al. 1999; Othman et al. 2016). By-passed hydrocarbon resources were delineated east of the existing wells in agreement with the result of the reflectivity attributes.

\section{Conclusion}

Integrating reflectivity and spectral frequency attributes have greatly improved reservoir detection, delineation and characterization in MUN onshore Niger delta field. Hydrocarbon saturated channel sands were independently mapped by high amplitudes (sweetness), low reflectivity attribute values and high-amplitude low-frequency spectral attributes. 
Analysis of data further show that Reflectivity attributes provided a better description of hydrocarbon content than the sweetness and spectral attributes, but are less sensitive to structure and exaggerated the shape and limits of the channel sands. However, spectral attributes seem to be more robust than the reflectivity attributes in providing subtle structural and stratigraphic details of the reservoir as well as delineating by-passed hydrocarbons in the field.

Acknowledgements We are grateful to Shell Petroleum Development Company of Nigeria for providing the 3D PSTM data for the study. Our thanks also go to World Bank, Africa Centre of Excellence in Oilfield Chemicals Research (ACE-CEFOR), UNIPORT; Jomo Kenyatta University of Agriculture and Technology (JKUAT) and RUFORUM for their support.

Open Access This article is licensed under a Creative Commons Attribution 4.0 International License, which permits use, sharing, adaptation, distribution and reproduction in any medium or format, as long as you give appropriate credit to the original author(s) and the source, provide a link to the Creative Commons licence, and indicate if changes were made. The images or other third party material in this article are included in the article's Creative Commons licence, unless indicated otherwise in a credit line to the material. If material is not included in the article's Creative Commons licence and your intended use is not permitted by statutory regulation or exceeds the permitted use, you will need to obtain permission directly from the copyright holder. To view a copy of this licence, visit http://creativecommons.org/licenses/by/4.0/.

\section{References}

Ahmad MN, Rowell P (2012) Application of spectral decomposition and seismic attributes to understand the structure and distribution of sand reservoirs within Tertiary rift basins of Gulf of Thailand. Search and Discovery. Article \#40992

Ajisafe YC, Ako BD (2013) 3D seismic attributes for reservoir characterization of "Y" field Niger delta. IS OR J Appl Geol Geophys $1(2): 23-31$

Bello R, Igwenagu CL, Onifade YS (2015) Cross plotting of rock properties for fluid and lithology discrimination using well data in a Niger delta oil field. J Appl Sci Environ Manag 19(3):536-546

Chopra S, Marfurt KJ (2007) Seismic attributes for prospect identification and reservoir characterization. Geophysical Development Series, No. 11. Houston, SEG Book, p 382

Dagogo T, Ehirim CN, Ebeniro JO (2016) Enhanced prospect definition using well and 4D seismic data in a Niger delta field. Int $\mathrm{J}$ Geosci 7:977-990

Doust H, Omatsola M (1990) Divergent and passive margin basins. Am Assoc Pet Geol Bull 48(1):201-238

Edigbue PI, Komolafe AA, Adesida AA, Itamuko OJ (2014) Hydrocarbon reservoir characterization of "Keke" field, Niger delta using 3 seismic and petrophysical data. Am J Sci Ind Res 5(2):73-80

Ehirim CN, Akpan AS (2017) Continuous wavelet transform based spectral decomposition of 3D seismic data for reservoir characterization in Oyi Field, se Niger Delta. Am J Appl Sci 14(8):766-771

Ehirim CN, Dagogo T (2016) Subsidence inferred from a time lapse reservoir study in a Niger delta field, Nigeria. Curr Res Geosci 6(2):98-106. https://doi.org/10.3844/ajgsp.2016.98.106

Ekwe AC, Onuoha KM, Osayande N (2012) Fluid and lithology discrimination using rock physics modelling and lambdamurho inversion: an example from onshore Niger Delta, Nigeria. Search and Discovery. Article \#40865. In: AAPG international conference and exhibition, Milan, Italy

Eshimokhai S, Akhirevbulu OE (2012) Reservoir characterization using seismic and well logs data (a case study of Niger Delta). Ethiop J Environ Stud Manag EJESM 5(4):597-603

Evamy BO, Herembourne J, Kameline P, Knap WA, Molloy FA, Rowlands PH (1978) Hydrocarbon habitat of Tertiary Niger delta. Am Asso Petrol Geol Bull 62:1-39

Goodway W, Chen T, Downton J (1997) Improved AVO fluid detection and lithology discrimination using Lamé petrophysical parameters; $\lambda \rho, \mu \rho \& \lambda / \mu$ fluid stack from $\mathrm{P}$ and $\mathrm{S}$ inversions. In: 67th annual international meeting, SEG, Expanded Abstracts, pp 183-186

Hamada GM (2004) Reservoir fluids identification using Vp/Vs ratio. Oil Gas Sci Technol 59(6):649-654

Hart BS (2008) Channel detection in 3-D seismic data using sweetness. AAPG Bull 92(6):733-742

Hilterman FJ (2001) Seismic amplitude interpretation. SEG/EAGE Distinguished Instructor Course No. 4

Mahmoud M, Ghorab M, Shasly T, Shibl A, Abuhagaza AA (2016) Reservoir characterization utilizing the well logging analysis of Abu Madi Formation, Nile Delta, Egypte. Egypt J Pet. https://doi. org/10.1016/j.ejpe.2016.11.003

Marfurt KJ, Kirlin RL (2001) Narrow-band spectral analysis and thinbed tuning. Geophysics 66:1274-1283

Mohamed AK, Ghazala HH, Mohamed L (2016) Integration between well logging and seismic reflection techniques for structural analysis and reservoir characterizations, Abu El Gharadig basin, Egypt. NRIAG J Astron Geophys. https://doi.org/10.1016/j.nrjag 2016.07.003

Othman AAA, Fathy M, Maher A (2016) Use of spectral decomposition technique for delineation of channels for solar gas discovery, offshore West Nile Delta, Egypt. Egypt J Pet 25:45-51

Partyka G, Gridley J, Lopez J (1999) Interpretational applications of spectral decomposition in reservoir characterization. Lead Edge 18:353-360

Reijers TJA (2011) Stratigraphy and sedimentology of the Niger Delta. Geologos 17(3):133-162. https://doi.org/10.2478/v1011 8-011-0008-3

Sanuade OA, Akanji AO, Oladunjoye IM, Olaojo AA, Fatoba JO (2017) Hydrocarbon reservoir characterization of "AY" field, deep-water Niger Delta using 3D seismic and well logs. Arab J Geosci 10:151

Sinha S, Routh PS, Anno PD, Castagna JP (2005) Spectral decomposition of seismic data with continuous wavelet transform. Geophysics 70(6):P19-P25. https://doi.org/10.1190/1.2127113

Tian L, Zhou D, Lin G, Jiang L (2010) Reservoir prediction using Poisson impedance in Qinhuangdao, Bohai Sea. In: SEG Denver 2010 annual meeting, pp 2261-2264

Tuttle MLW, Brownfield ME, Charpentier RR (1999) The Niger Delta Petroleum System: Niger Delta Province, Nigeria, Cameroon, and Equatorial Guinea, Africa. Tertiary Niger Delta (Akata-Agbada) Petroleum System (No. 701901). Open-File Report 99-50-H

Wei L, Dali Y, Wenfeng W, Wurong W, Shenghe W, Jian L, Depo C (2019) Fusing multiple frequency-decomposed seismic attributes with machine learning for thickness prediction and sedimentary facies interpretation in fluvial reservoirs. J Pet Sci Eng 177:1087-1102

Publisher's note Springer Nature remains neutral with regard to jurisdictional claims in published maps and institutional affiliations. 